\title{
Thermal shock properties of chemically toughened borosilicate glass ${ }^{1}$
}

\author{
O. Peitl *, E.D. Zanotto
}

Vitreous Materials Laboratory (LaMaV), Department of Materials Engineering (DEMa), Federal University of São Carlos (UFSCar), 13565-905 São Carlos, SP, Brazil

\begin{abstract}
This paper describes an experimental test of the unified theory of thermal shock. A borosilicate glass $\left(78.1 \% \mathrm{SiO}_{2-}\right.$ $13.3 \% \mathrm{~B}_{2} \mathrm{O}_{3}-4.7 \% \mathrm{Na}_{2} \mathrm{O}-3.4 \% \mathrm{Al}_{2} \mathrm{O}_{3}$ ) subjected to ion-exchange in molten $\mathrm{KNO}_{3}$, was used. The theory predicts the critical temperature difference for fracture initiation by thermal shock; however, it overestimates the number of cracks which propagate simultaneously. Despite that fact, taken into account the numerous assumptions of the theoretical model and the possible experimental errors, our results indicate a fair agreement between theory and experiment. (c) 1999 Elsevier Science B.V. All rights reserved.
\end{abstract}

\section{Introduction}

Damage caused by thermal shock has long been a matter of concern to both manufacturers and users of brittle materials such as ceramics and glasses. Recently, however, the application of scientific principles has resulted in a better understanding of the variables affecting the thermalmechanical properties of these materials.

Glasses are model materials for basic studies of thermal-mechanical properties since they show an almost ideal brittle behavior, are isotropic and lack volumetric defects such as grain boundaries, pores, and inclusions [1]. In addition to these factors, from a technological point of view, borosilicate glasses of the Pyrex variety have been widely used

\footnotetext{
${ }^{*}$ Corresponding author. E-mail: opeitl@power.ufscar.br

${ }^{1}$ The results described in this article were judged by an international committee and were considered to be the best poster of scientific nature presented at the III Brazilian Symposium on Glass and Related Materials, Bonito, Brazil, 1998.
}

for many years in the manufacture of products such as transparent high pressure seals, beakers, test tubes and coffee percolators. Such products have a limited lifespan due to the severe conditions to which they are subjected daily, particularly sudden temperature variations.

Although the theoretical strength of glass is larger than $10 \mathrm{GPa}$, its practical strength when in actual use is only about $50 \mathrm{MPa}$ [1]. Glasses are susceptible to catastrophic fracture under high rates of heat transfer. Their inherent fragility, coupled with superficial microscopic flaws [2], is the cause of this low resistance to fracture.

The technique of ion-exchange is one of the most effective alternatives to minimize the deleterious effect of these flaws [3-5] because it produces compressive stresses on the glass surface by substituting the smaller ion $\left(\mathrm{Na}^{+}\right)$in the glass for a larger ion $\left(\mathrm{K}^{+}\right)$, a component of a molten salt bath $\left(\mathrm{KNO}_{3}\right)$. Strengthened glass, therefore, requires higher stresses for catastrophic crack initiation than does a glass without residual compressive stresses $[6,7]$. 
The quantitative evaluation of cracking resistance by thermal shock in water requires knowledge of parameters that are difficult to collect, such as the coefficient of heat transfer $(h-$ which varies between 5 and $50 \mathrm{~kJ} / \mathrm{m}^{2}{ }^{\circ} \mathrm{C}$ ) and a geometric factor $(S)$. However, when certain conditions of thermal shock testing are maintained constant, these factors can be eliminated, as will be shown later. The objective of this article is to address the unified theory of thermal shock in almost ideal conditions, using both virgin and chemically toughened glasses.

\section{Thermal-mechanical stresses}

Stresses may be developed when a brittle material is subjected to sudden variations in temperature. Resistance to fracture under such conditions is called 'thermal shock damage resistance'. The effect of thermal shock on the materials strength depends on the level and distribution of stress in the body, how long the body stays under stress, and on properties such as homogeneity, porosity, and pre-existing cracks.

According to Kingery [8], a simple criterion is to consider ideally elastic materials (such as glasses) that fracture when the tensile surface stress reaches a critical magnitude. A crack is initiated when the maximum thermal stress, $\sigma_{\mathrm{T}}$, overcomes the fracture stress, $\sigma_{R}$, of the material. The maximum biaxial thermal stress in a infinite slab is given by the following equation [8]:

$\sigma_{\mathrm{T}}=\frac{E \alpha \Delta T}{1-\mu}$,

where $E$ is Young's modulus, $\alpha$ is the linear thermal expansion coefficient, $\mu$ is Poisson's coefficient and $\Delta T$ is the maximum temperature difference between the surface and the core of the body (which is reached at some short time interval after the thermal shock). However, the coefficient of heat transfer and thermal conductivity must also be considered. In practical terms, the magnitude of stress is expressed in terms of a dimensionless parameter, Biot's modulus $(\beta)$, represented by Eq. (2) [8]:
$\beta=\frac{r_{\mathrm{M}} h}{k}$,

where $r_{M}$ is half the thickness of the slab or cylinder radius, $h$, the heat transfer coefficient and $k$, the coefficient of thermal conductivity.

For small Biot's modulus the thermal stress indicated in Eq. (1) is reduced proportionately by a $\psi$ factor, according to Eq. (3):

$\sigma_{\mathrm{T}}=\frac{\psi E \alpha \Delta T}{1-\mu}$.

The attenuating factor, $\psi$, varies between 0 and $1(\beta=\infty)$ and is expressed as a function of Biot's modulus. Thus, by rearranging Eq. (3), the critical temperature differential necessary for crack propagation $\left(\Delta T_{\mathrm{C}}\right)$ is expressed by

$\Delta T_{\mathrm{C}}=\frac{\sigma_{\mathrm{R}}(1-\mu)}{\psi E \alpha}$,

where $\sigma_{\mathrm{R}}$ is the body's fracture stress.

Although Biot's modulus considers the dimensions of the ceramic body, the materials behavior under thermal shock is also influenced by the object's geometry. To this end, a geometric factor $(S)$ is introduced into Eq. (4)

$\Delta T_{\mathrm{C}}=\frac{\sigma_{\mathrm{R}}(1-\mu)}{\psi E \alpha} \cdot S$.

For $\beta>20$, cooling occurs at such a rate that the surface reaches the final temperature before the average temperature of the body varies, so $\psi \sim 1$ [8]. This $\psi$ is achieved, for example, when a glass $\left(k=4 \mathrm{~J} / \mathrm{m} \mathrm{s}^{\circ} \mathrm{C}\right)$ is cooled in water $\left(h=4 \times 10^{4} \mathrm{~J} / \mathrm{m}^{2}\right.$ $\mathrm{s}{ }^{\circ} \mathrm{C}$ ) and $r_{\mathrm{M}}$ (slab thickness or cylinder radius) is equal to or larger than $4 \mathrm{~mm}$.

The term $\sigma_{\mathrm{R}}(1-\mu) / \alpha E$ in Eq. (5) is called $R$, which reduces it to

$\Delta T_{\mathrm{C}}=R S$,

where $R$ can be viewed as a material's resistance factor to crack initiation in cases where a high rate $(\beta>20)$ of heat transfer occurs.

These equations can be applied to isotropic bodies, assuming that the physical properties $(h, K$, $\alpha$ and $E$ ) are independent of the temperature. This 
assumption is only an approximation in most practical cases.

\section{Unified theory of thermal shock}

It must again be emphasized that the equations shown earlier herein represent only the thermoelastic fracture initiation process, which is of vital importance to brittle materials. However, resistance to thermal shock can also be evaluated by measuring its effects on the properties and physical conditions of the material, such as, for instance, loss of mechanical strength due to crack growth. Thus, for materials that already contain cracks or relatively large defects, the degree of damage can be more important than the nucleation of new cracks. In this case, the parameters that affect the spreading of these cracks have the largest effect.

Therefore, a method of measuring resistance to thermal shock is to first evaluate the degree of difficulty of crack nucleation and then measure the degree of damage caused by the shock after the cracks have spread. The degree of damage can be evaluated if one compares the original mechanical strength to that obtained after a single thermal shock.

Hasselman [9] assumed that the driving force for crack propagation is supplied by the elastic strain energy stored immediately prior to the fracture and that this released energy is transformed into surface energy $\left(\gamma_{\mathrm{wf}}\right)$. He derived an equation to express damage resistance:

$R^{\prime \prime \prime \prime}=\frac{E \gamma_{\mathrm{wf}}}{\sigma_{\mathrm{R}}^{2}(1-\mu)}$.

Although not explicit in Eq. (7) the $R^{\prime \prime \prime \prime}$ parameter relates to the number and length of cracks that propagate.

It can be noted in the expressions that represent the parameters $R$ (resistance to fracture initiation) and $R^{\prime \prime \prime \prime}$ (resistance to damage), that simultaneous maximization of both is impossible. In other words, when maximizing the resistance to fracture initiation one risks an increase of damage caused by thermal shock, and vice-versa.

In a series of articles, Hasselman and co-authors [9-13], studied the conditions for crack propagation caused by thermal shock, based on a different model. A mechanical model was proposed by Gebauer, Krohn and Hasselman [13], assuming an elastic, flat, brittle solid plate of unit thickness with $N_{\mathrm{S}}$ (cracks/unit-area) parallel cracks of equal length. The plate is uniformly precompressed with a strain $\varepsilon_{0}$ and constrained in a direction perpendicular to the cracks. The plate is uniformly cooled through a temperature difference, assuming that the cracks propagate simultaneously without interaction. The authors [13] suggested that the critical variation of temperature $\left(\Delta T_{\mathrm{C}}\right)$ required for propagation of pre-existing superficial defects can be expressed by

$\Delta T_{\mathrm{C}}=\frac{\varepsilon_{0}}{\alpha}+\left[\frac{2 \gamma_{\mathrm{ef}}}{\pi E \alpha^{2} l}\right]^{1 / 2}\left(1+2 \pi N_{\mathrm{S}} l^{2}\right)$,

where $N_{\mathrm{S}}$ is the number of critical defects per unit area, $l$, the half-length of the critical defects that propagate simultaneously, $\gamma_{\mathrm{ef}}$, the effective fracture energy for crack initiation and $E$, the modulus of elasticity. The other parameters were previously defined. In Eq. (8), the second term on the right hand side represents the critical temperature difference for the uncompressed plate $\left(\varepsilon_{0}=0\right)$.

After propagation by thermal shock, the final crack length, $l_{\mathrm{f}}$, of defects having initial length $l_{0}$, is given by the following equation $[12,13]$

$l_{\mathrm{f}}=\frac{1}{4 \pi N_{\mathrm{S}} l_{0}}$.

Thus, the final crack length is inversely proportional to the initial defect size and to the number of cracks which simultaneously propagate. Eq. (9) is only valid for small initial crack lengths $\left(2 \pi N_{\mathrm{S}} l_{0}^{2} \ll 1\right)$.

\section{Experimental test of the unified theory of thermal shock}

In the previous sections we introduced the problem and summarized the unified theory of thermal shock. This part describes the materials and methods used, the experimental results, their analysis based on the theory and our conclusions. 
For an experimental evaluation of the theories presented (classical theory, Eq. (5) and unified theory, Eq. (8)), the following properties must be determined: $\Delta T_{\mathrm{C}}, \sigma_{\mathrm{R}}, E, \mu, \alpha, \gamma, l_{0}$ and $N_{\mathrm{S}}$ before and after the ion-exchange treatment. Previous studies demonstrate that ion-exchange elevates the fracture stress, $\sigma_{\mathrm{R}}[5,6]$ and the critical temperature difference, $\Delta T_{\mathrm{C}}[6,7]$. Of the remaining properties, the literature covers only the effect of ion-exchange on the Young modulus $(E)$, discussed by Mackenzie and Wakaki [14].

\subsection{Materials and methods}

Rectangular samples of a commercial borosilicate glass 'Termex', used in the manufacture of coffee percolators, measuring $14 \times 2.5 \mathrm{~mm}$ were employed to determine the (bending) fracture stress $\left(\sigma_{\mathrm{f}}\right)$, microhardness $\left(H_{\mathrm{v}}\right)$ and the modulus of elasticity by extensometry. For the remaining tests, $6 \mathrm{~mm}$ diameter cylindrical samples were used. The chemical analysis of the glass used is shown in Table 1 .

Two other thermal properties were determined: the coefficient of linear thermal expansion $\left(\alpha=4.1 \times 10^{-6}{ }^{\circ} \mathrm{C}^{-1}\right)$ and the glass transition temperature $\left(T_{\mathrm{g}} \sim 540^{\circ} \mathrm{C}\right)$. Ion exchange treatments were applied at $446 \pm 5^{\circ} \mathrm{C}$ and $480 \pm 5^{\circ} \mathrm{C}$ for periods of $2,4,8,16,24,32$ and $64 \mathrm{~h}$ in a $\mathrm{KNO}_{3}$ bath using an AISI 316 stainless steel container with capacity for 30 samples. Upon conclusion of the treatment, the samples were allowed to cool in the open air, washed and submerged in distilled water for $24 \mathrm{~h}$, and then dried. Part of these samples was destined for a four-point bending test. The other samples were measured for Vickers' microhardness and to determine profiles of potassium concentrations [15].

The thermal shock tests were done in water at ambient temperature, with both chemically treated specimens $\left(480^{\circ} \mathrm{C}-8 \mathrm{~h}\right)$ and untreated samples. The thermal shock test temperature difference $(\Delta T)$ was from $120^{\circ} \mathrm{C}$ to $450^{\circ} \mathrm{C}$. A container was made specifically for this purpose (Fig. 1), which allowed monitoring and guaranteed homogeneous temperatures of the samples during the test. To confirm the results of thermal shock tests on sharp edged samples, tests were also performed, under
Table 1

Chemical analysis of the termex glass used

\begin{tabular}{lc}
\hline Composition & Weight $(\%)$ \\
\hline $\mathrm{SiO}_{2}$ & 78.1 \\
$\mathrm{~B}_{2} \mathrm{O}_{3}$ & 13.3 \\
$\mathrm{Na}_{2} \mathrm{O}$ & 4.7 \\
$\mathrm{Al}_{2} \mathrm{O}_{3}$ & 3.4 \\
$\mathrm{CaO}$ & 0.28 \\
$\mathrm{MgO}$ & 0.16 \\
$\mathrm{~K}_{2} \mathrm{O}$ & 0.05 \\
$\mathrm{Fe}_{2} \mathrm{O}_{3}$ & 0.03 \\
\hline
\end{tabular}

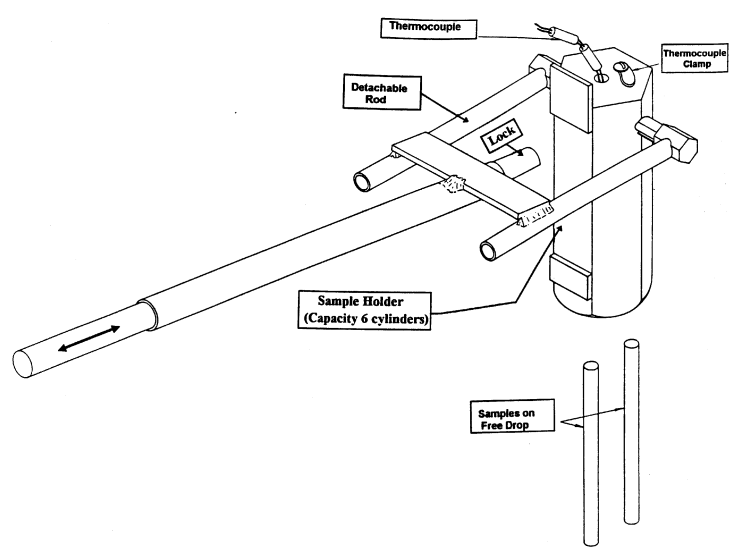

Fig. 1. Thermal shock device.

three different additional conditions, i.e., on samples with rounded edges, with edges isolated by a mineral coating, and with edges isolated by a diatomite based ceramic paste.

The modulus of elasticity of samples treated with $\mathrm{KNO}_{3}$ at $480^{\circ} \mathrm{C}$ for $8 \mathrm{~h}$ and those of untreated samples were determined by three different methods: pulse echo, flexural resonance and extensometry. The Poisson modulus was determined by the pulse-echo technique.

The exchanged potassium ion profiles were obtained by means of electron microprobe analysis of samples treated at $480^{\circ} \mathrm{C}$ for $2,4,8$ and $24 \mathrm{~h}$.

\section{Results}

Fig. 2 shows the 4-point bending fracture strength $\left(\sigma_{\mathrm{f} 4}\right)$ as a function of chemical treatment time at $446^{\circ} \mathrm{C}$ and $480^{\circ} \mathrm{C}$. In the initial stage of 


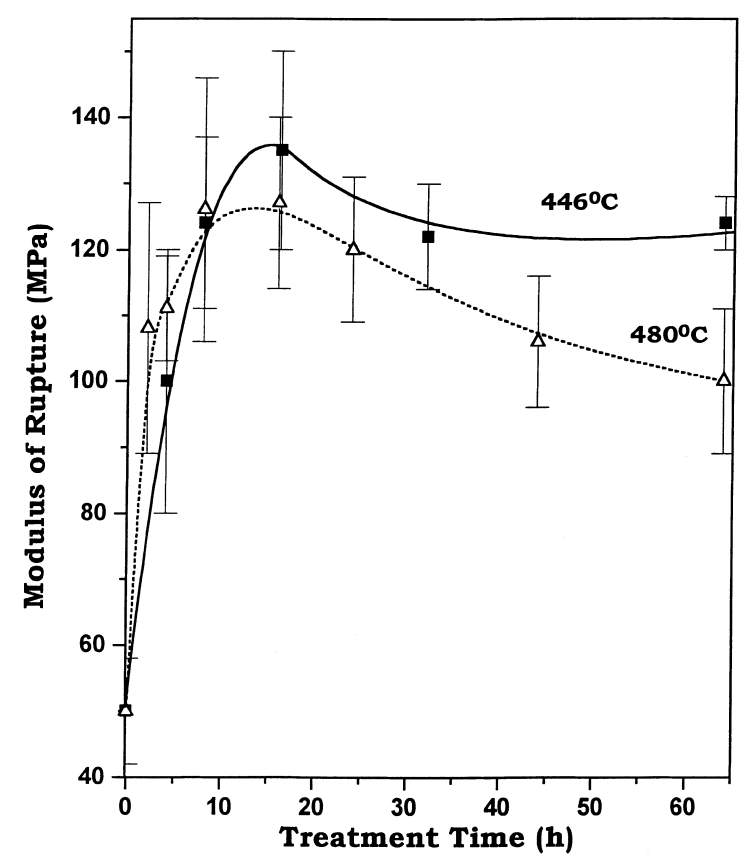

Fig. 2. Modulus of rupture $\left(\sigma_{\mathrm{f} 4}\right)$ as a function of chemical treatment time at $446^{\circ} \mathrm{C}(\square)$ and $480^{\circ} \mathrm{C}(\triangle)$. Lines are drawn as guides for the eye.

the ion-exchange process there is an increment in strength that reaches a maximum between 8 and $16 \mathrm{~h}$ of treatment and then decreases. As to be expected, degeneration of the strenght occurs due to structural relaxation at the highest temperature.

Fig. 3 illustrates the results of Vickers' microhardness $\left(H_{\mathrm{v}}\right)$ measurements for samples treated at $480^{\circ} \mathrm{C}$ for different periods of time, as well as the modulus of rupture (for comparison). The chemical treatment increases the superficial microhardness. After the increase, a maximum is achieved at about $8 \mathrm{~h}$, after which it decreases. The strength shows a similar dependence.

The relative intensities of the potassium $\mathrm{K}_{\alpha}$ line (average of six measurements) determined by electron microprobe technique, for samples treated at $480^{\circ} \mathrm{C}$ for several time periods, are shown in Fig. 4.

A comparison of Figs. 2 and 4 shows that the initial increase of strength is compatible with the growth of the exchanged layer. For time periods in

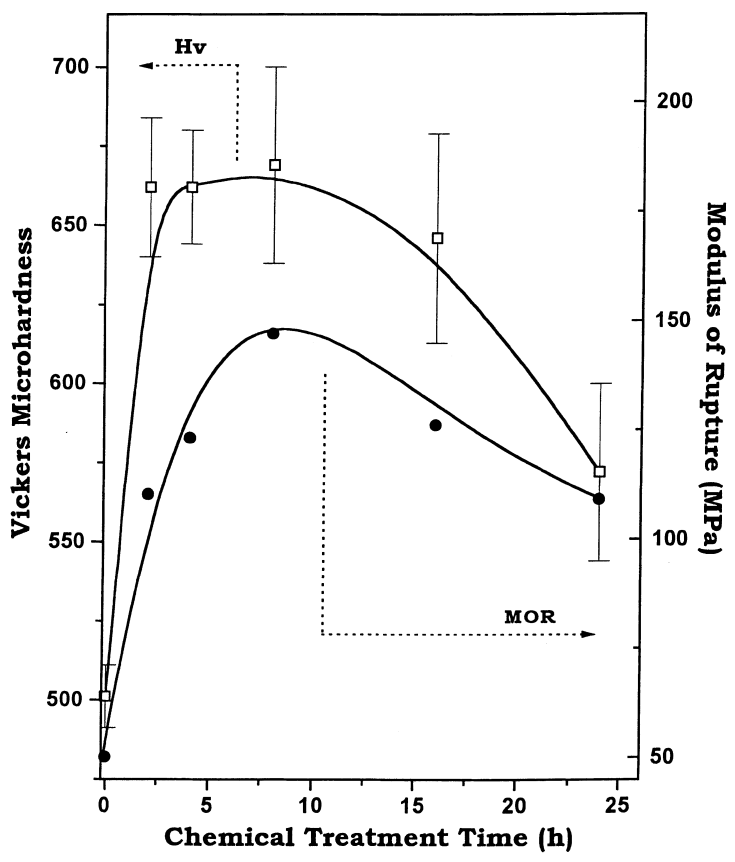

Fig. 3. Vickers' microhardness $(\square)$ and modulus of rupture (•) as a function of chemical treatment time at $480^{\circ} \mathrm{C}$. Lines are drawn as guides for the eye.

excess of $10 \mathrm{~h}$, however, the fracture strength decreases despite the increase in exchanged layer depth. We conclude that structural relaxation (that relieves residual stress) becomes preponderant to the mechanism of ion-exchange strengthening. Considering the variables presented, the treatment showing the best performance $\left(480^{\circ} \mathrm{C}\right.$ for $\left.8 \mathrm{~h}\right)$ was used for all subsequent tests.

Fig. 5 presents the results of the retained strength after thermal shock for both the as-received specimens and for samples chemically treated at $480^{\circ} \mathrm{C}$ for $8 \mathrm{~h}$. We note that, in addition to rupture stress, the exchange treatment increases the critical temperature difference for crack propagation $\left(\Delta T_{\mathrm{C}}\right)$. We also note that the retained strength of both types of samples is identical for thermal shocks greater than $\Delta T_{\mathrm{C}}$. No alteration in the critical difference of temperature was observed when the type of extremity - sharp edged, rounded, or thermally isolated - was modified. We thus conclude that any edge effect did not affect these experiments. 


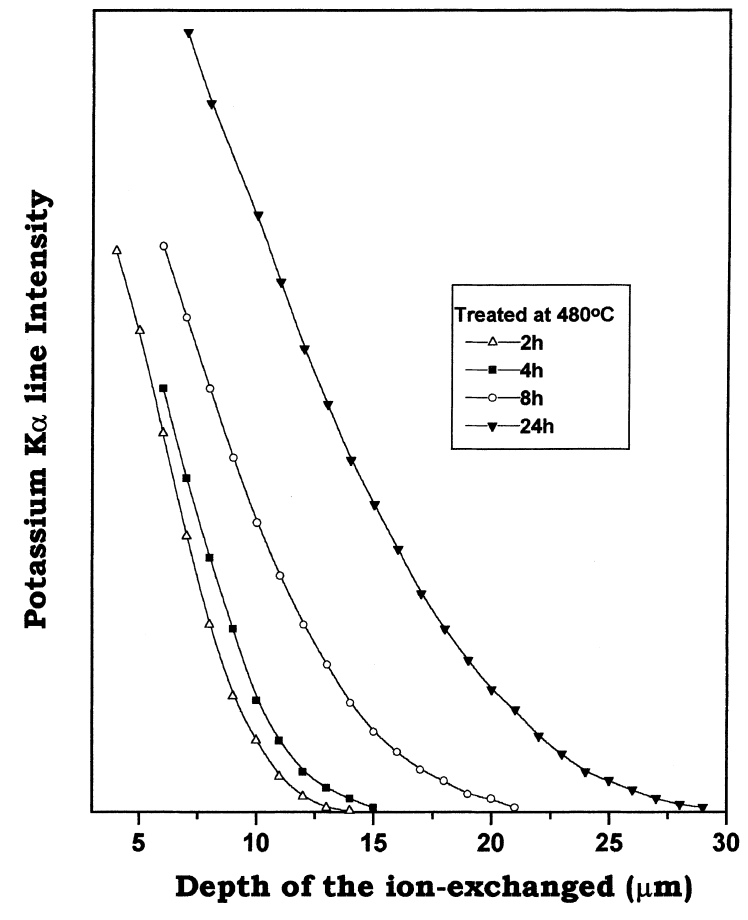

Fig. 4. Profile of potassium $\mathrm{K}_{\alpha}$ line intensity in relation to depth of the ion-exchanged layer at $480^{\circ} \mathrm{C}$ for periods of $2(\triangle), 4(\square)$, $8(\bigcirc)$ and $24(\boldsymbol{\nabla})$ h. Lines are drawn as guides for the eye.

The modulus of elasticity was determined by means of three different techniques on both as-received and on samples treated at $480^{\circ} \mathrm{C}$ for $8 \mathrm{~h}$. Table 2 presents the experimental results. Poisson's coefficient increased by $15 \%$. However, it must be kept in mind that the experimental techniques used determine the samples' volumetric elastic properties and are not affected by the thin compressed layer, within errors of measurement.

Table 3 presents a summary of other physical properties obtained experimentally, as well as literature data for borosilicate glass.

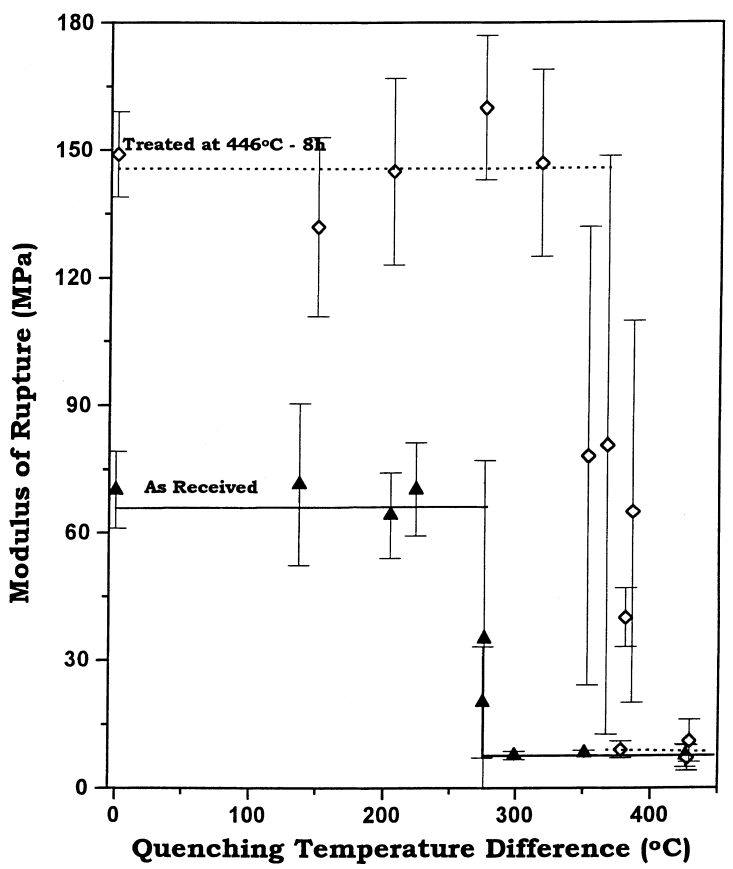

Fig. 5. Comparative thermal shock behavior of virgin glass $(\mathbf{\Delta})$ and chemically treated borosilcate glass $(\diamond)$ subject to a water quench. Lines are drawn as guides for the eye.

\section{Discussion}

\subsection{Classical theory of thermal shock}

As demonstrated by Eq. (5) the critical temperature difference of thermal shock for crack propagation depends on the attenuation factor $(\Psi)$, which is a function of Biot's modulus, and on a geometric factor $(S)$. The absolute Biot's modulus for thermal shock in water is difficult to determine, since the coefficient of heat transfer $(h)$ varies between 5 and $40 \mathrm{~kJ} / \mathrm{m}^{2} \mathrm{~s}{ }^{\circ} \mathrm{C}$. However, in their calculations, some authors such as Bad-

Table 2

Elastic properties $(E, G, \mu)$ of the borosilicate glass used (Termex)

\begin{tabular}{llll}
\hline Property & As received & Treated with $\mathrm{KNO}_{3}$ & Technique \\
\hline$E(\mathrm{GPa}) \pm 1 \%$ & 59.7 & 60.8 & Pulse echo \\
$E(\mathrm{GPa}) \pm 2 \%$ & 61.6 & 64.0 & Extensometry \\
$E(\mathrm{GPa}) \pm 2 \%$ & 50.4 & 52.2 & Flexural resonance \\
$G(\mathrm{GPa}) \pm 1 \%$ & 25.5 & 25.5 & Pulse-echo \\
$\mu \pm 2 \%$ & 0.17 & 0.19 & Pulse-echo \\
\hline
\end{tabular}


Table 3

Physical properties of Termex glass

\begin{tabular}{lccl}
\hline Properties & As received & Treated $\left(8 \mathrm{~h}-480^{\circ} \mathrm{C}\right)$ & Technique or source \\
\hline$\left\langle\sigma_{\mathrm{f} 4}\right\rangle(\mathrm{MPa}) \pm 15 \%$ & 68 & 147 & 4 Point bending \\
$\rho\left(\mathrm{g} / \mathrm{cm}^{3}\right) \pm 1 \%$ & 2.21 & 2.21 & Pichnometry \\
$\left\langle\Delta T_{\mathrm{c}}\right\rangle\left({ }^{\circ} \mathrm{C}\right) \pm 7 \%$ & 276 & 370 & Thermal shock \\
$H_{\mathrm{v}} \pm 4 \%$ & 501 & 669 & Microhardness \\
$\alpha\left({ }^{\circ} \mathrm{C}^{-1}\right) \pm 5 \%$ & $4.2 \times 10^{-6}$ & $4.0 \times 10^{-6}$ & Dilatometry \\
$k\left(\mathrm{~J} / \mathrm{m} \mathrm{s}{ }^{\circ} \mathrm{C}\right)$ & 1.3 & & Handbook of glass [18] \\
$\gamma_{\mathrm{ef}}\left(\mathrm{J} / \mathrm{m}^{2}\right)$ & & & Ref. [16] \\
Air $\left(22^{\circ} \mathrm{C}\right), 20 \% \mathrm{RH}$ & 4.7 & & Ref. [16] \\
Air $\left(22^{\circ} \mathrm{C}\right), 40 \% \mathrm{RH}$ & 4.0 & & Ref. [16] \\
Water $\left(20^{\circ} \mathrm{C}\right)$ & 2.5 & & Ref. [17] \\
$\mathrm{N}_{2}(1)\left(77^{\circ} \mathrm{K}\right)$ & 4.7 & &
\end{tabular}

aliance et al. [19] applied the upper limit of $40 \mathrm{~kJ} /$ $\mathrm{m}^{2} \mathrm{~s}{ }^{\circ} \mathrm{C}$, while others such as Kingery [8] used 17 $\mathrm{kJ} / \mathrm{m}^{2} \mathrm{~s}{ }^{\circ} \mathrm{C}$. Due to this difficulty, in this study we calculated $\beta$ for the entire range of the heat transfer coefficient, from which $37<\beta<90$. According to Kingery [8], however, when $\beta>20, \Psi$ is approximately 1 . Therefore, using either of the sources mentioned herein, the attenuation factor is approximately 1 .

When the Biot modulus of the untreated samples is compared to those of chemically treated specimens, the only physical parameter that could be altered is the thermal conductivity $(k)$. An estimate was made of the variation of $k$ using Ratclifte's [20] empirical parameters supposing that all the sodium ions of the samples' surfaces were exchanged for potassium. The value of $1.3 \mathrm{~J} /$ $\mathrm{m} \mathrm{s}{ }^{\circ} \mathrm{C}$ was obtained, which is equal to that presented in Table 3. Thus, we conclude that $\Psi_{\mathrm{UT}}=\Psi_{\mathrm{T}} \simeq 1$. Because the geometry of the treated and untreated samples is the same, the geometric factor is not altered due to chemical treatment, and so $S_{\mathrm{UT}}=S_{\mathrm{T}}$.

Eq. (5) gives the theoretical ratio between the critical temperature difference of the chemically treated glass $\left(\Delta T_{\mathrm{C}_{\mathrm{T}}}\right)$ and that of the untreated glass $\left(\Delta T_{\mathrm{C}_{\mathrm{UT}}}\right)$ by means of the following expression:

$\frac{\Delta T_{\mathrm{C}_{\mathrm{T}}}}{\Delta T_{\mathrm{C}_{\mathrm{UT}}}}=\frac{\sigma_{\mathrm{R}_{\mathrm{T}}}\left(1-\mu_{\mathrm{T}}\right)}{\sigma_{\mathrm{R}_{\mathrm{UT}}}\left(1-\mu_{\mathrm{UT}}\right)} \frac{E_{\mathrm{UT}} \alpha_{\mathrm{UT}}}{E_{\mathrm{T}} \alpha_{\mathrm{T}}}$.

We emphasize, however, that the stress required to initiate crack propagation by thermal shock
$\left(\sigma_{\mathrm{R}_{\mathrm{T}}}\right.$ or $\left.\sigma_{\mathrm{R}_{\mathrm{UT}}}\right)$ differs from the strength measured in a four-point bending test $\left(\sigma_{\mathrm{f} 4}\right)$. This fact is evident from the publications of Ishitsuka et al. [21] and Migliore Jr. and Zanotto [22], who explain that the difference between the rupture stresses determined in four-point bending tests and the rupture stress in tensile tests is due to the difference between the effective surface area of the test body that is subjected to tensile stresses. In other words, during thermal shock the entire surface of the test body is subjected to tensile stresses, while in a four-point bending test only a small part of the sample surface is subjected to tensile stresses.

It is possible to correlate the rupture stress in a pure tensile test (or thermal shock test) and that determined by a four-point bending test, based on Weibull's statistics

$\frac{\sigma_{\mathrm{R}}}{\sigma_{\mathrm{f} 4}}=\left[\frac{m+2}{8(m+1)^{2}}\right]^{1 / m}$,

where $m$ is Weibull's modulus.

Table 4 presents the results of Weibull's modulus as well as the strength under thermal shock (pure tensile), $\sigma_{\mathrm{R}}$, calculated from Eq. (11) for both types of samples.

Table 4

Results of Weibull's modulus

\begin{tabular}{llll}
\hline Sample condition & $m$ & $\sigma_{\mathrm{R}} / \sigma_{\mathrm{f} 4}$ & $\sigma_{\mathrm{R}}(\mathrm{MPa})$ \\
\hline As received & 7.02 & 0.58 & 39.7 \\
Treated $\left(8 \mathrm{~h}-480^{\circ} \mathrm{C}\right)$ & 5.57 & 0.50 & 74.1 \\
\hline
\end{tabular}


Mackenzie and Wakaki [14] concluded that ionexchange treatments can increase the modulus of elasticity of glass surfaces $\left(E_{\mathrm{T}}\right)$, but upon observing the experimental results (Table 1), only an increase of $3 \%$ is noted. However, it must be kept in mind that the techniques used to determine the modulus of elasticity are inadequate to measure the modulus of elasticity of a superficial layer only a few microns thick. Yamane and Mackenzie [23], however, suggested a method to estimate the elasticity modulus of a surface layer in an indirect manner, using Vickers' microhardness, which is given by the following equation:

$H_{\mathrm{v}}=0.19\left[\frac{\Omega}{6(1+\mu)(1-2 \mu)}\right]^{1 / 2} E$,

where $\Omega$ is the relative average strength of the chemical bonding, which is related to the fraction of non-bridging oxygens $\left(\mathrm{Si}-\mathrm{O}-\mathrm{R}^{+}\right)$, using vitreous silica as standard, for which $\Omega$ is 1 . The superficial modulus of elasticity can be estimated by determining the ratio between the microhardness of treated and untreated glass, as shown in Eq. (13).

$\frac{H_{\mathrm{V}_{\mathrm{T}}}}{H_{\mathrm{v}_{\mathrm{UT}}}}=\left[\frac{\left(1+\mu_{\mathrm{UT}}\right)\left(1-2 \mu_{\mathrm{UT}}\right)}{\left(1+\mu_{\mathrm{T}}\right)\left(1+2 \mu_{\mathrm{T}}\right)}\right]^{1 / 2} \frac{E_{\mathrm{T}}}{E_{\mathrm{UT}}}$.

In the evaluation of $E_{\mathrm{T}}$ by Eq. (13) we assume that ion-exchange does not alter the average number of non-bridging oxygen because the number of alkaline ions is kept constant; thus, $\Omega_{\mathrm{T}}=\Omega_{\mathrm{ST}}$. Calculation of the superficial modulus of elasticity for a glass treated at $480^{\circ} \mathrm{C}$ for $8 \mathrm{~h}$ resulted in $84 \mathrm{GPa}$, representing a $44 \%$ increase in relation to untreated glass.

An estimate was also done of the alteration of the thermal expansion coefficient with chemical treatment, using empirical factors proposed by Turner [24] and by Appen [25], through the glass composition. Calculation of the expansion coefficient using the parameters of Turner produces results that are close to the experimental data. However, using the Appen factors produces quite different results. For this reason only experimental data were used in the calculations of this study. The chemical treatment reduced the coefficient of thermal expansion of Termex glass from
$4.2 \times 10^{-6}{ }^{\circ} \mathrm{C}$ to $4.0 \times 10^{-6}{ }^{\circ} \mathrm{C}^{-1}$, a decrease within errors of measurement.

Having determined all the necessary physical parameters, we now address the classical theory of thermal shock, inserting the experimental data into Eq. (10). Thus, we have

$$
\left[\frac{\Delta T_{\mathrm{C}_{\mathrm{T}}}}{\Delta T_{\mathrm{C}_{\mathrm{UT}}}}\right]_{\mathrm{Th}} \cong 1.36
$$

Fig. 5 indicates that the decrease in mechanical strength of treated glass occurs within a temperature interval of $355^{\circ} \mathrm{C}$ to $386^{\circ} \mathrm{C}$. Considering this temperature range in the calculations and taking into account the uncertainty in the experimental $\Delta T_{\mathrm{C}}$, the experimental ratio above defined is

$$
1.29 \leqslant\left[\frac{\Delta T_{\mathrm{C}_{\mathrm{T}}}}{\Delta T_{\mathrm{C}_{\mathrm{UT}}}}\right]_{\mathrm{EXP}} \leqslant 1.40 .
$$

We, therefore, conclude that the classical theory of thermal stresses agrees with the experimental result.

\subsection{Unified theory of thermal shock}

If the initial defect length, $l_{0}$, on the uncompressed glass surface $(\varepsilon=0)$ is relatively small $\left(2 \pi N_{\mathrm{S}} l_{0}^{2} \ll 1\right)$, Eq. (8) reduces to

$\Delta T_{\mathrm{C}}=\left[\frac{2 \gamma_{\mathrm{ef}}}{\pi E \alpha^{2} l_{0}}\right]^{1 / 2}$.

Considering that there is negligible energy dissipation by plastic deformation and that no interaction with microstructure occurs during crack propagation in glasses, to a good approximation, the work of fracture is similar to the effective surface energy for crack propagation; $\gamma_{\mathrm{wf}} \cong \gamma_{\mathrm{ef}}$. Hence, by using the data of Tables 2 and 3 for untreated borosilicate glass, with the published $\gamma_{\mathrm{ef}}$ for borosilicate glass in water [16] $\left(\sim 2.5 \mathrm{~J} / \mathrm{m}^{2}\right)$ into Eq. (14) we have

$\Delta T_{\mathrm{C}_{\mathrm{UT}}}=1.23\left(l_{0}\right)^{-1 / 2}$.

The initial crack length, $l_{0}$, can be calculated by a fracture mechanics model [26], using the experimental $\sigma_{\mathrm{f} 4}$ (4 point bending strength, in air, at room temperature), $E$ (pulse-echo values) and literature data for $\gamma_{\mathrm{ef}}$ 
$l_{0}=\frac{2 E^{\bullet} \gamma_{\mathrm{ef}}}{\pi\left(1.12 \sigma_{\mathrm{f} 4}\right)^{2}}$,

where $E^{\bullet}$ identifies with the Young modulus $(E)$ in plane stress (thin plates) and with $E /\left(1-v^{2}\right)$ in plane strain (thick plates) [26].

It can be seen in Tables 2 and 3, that for $20^{\circ} \mathrm{C}$ and $40 \%$ humidity (approximate conditions of the bending test) $\gamma_{\mathrm{ef}} \sim 4 \mathrm{~J} / \mathrm{m}^{2}, E=59.7 \pm 0.5 \mathrm{GPa}$ and $\sigma_{\mathrm{f} 4}=68 \pm 10 \mathrm{MPa}$ for the untreated glass. Thus, considering plane strain, the initial length, $l_{0}$, of the critical defects is, therefore, $(2.6 \pm 0.7) \times 10^{-5}$ $\mathrm{m}$. The result of the introduction of this $l_{0}$ into Eq. (15) is that $\Delta T_{\mathrm{C}_{\mathrm{UT}}}$ is in the range $215-285^{\circ} \mathrm{C}$, while the experimental result was $275^{\circ} \mathrm{C}$. Thus, experimental and calculated $\Delta T_{\mathrm{C}}$ agree within errors of measurement and uncertainties of calculations.

The first term of Eq. (8), $\varepsilon_{0} / \alpha$, relates to a compressed surface. Applying Hooke's law for uniaxially constrained materials, $\sigma_{0}=E \varepsilon_{0}$, so $\varepsilon_{0} /$ $\alpha=\sigma_{0} / E_{\mathrm{T}} \alpha_{\mathrm{T}}$, where $\sigma_{0}=\sigma_{\mathrm{RT}}-\sigma_{\mathrm{RUT}}$. From Table 2 and Table 4 , it can be calculated that the chemical treatment increases the critical difference of temperature by $\left(\sigma_{0} / \alpha\right)=102^{\circ} \mathrm{C}$. This result is in agreement with the experimental results of Fig. 5 $\left(\Delta T_{\mathrm{C}_{\mathrm{T}}}-\Delta T_{\mathrm{C}_{\mathrm{UT}}}\right)=80 \leftrightarrow 113^{\circ} \mathrm{C}$. Therefore, Hasselman's theory also predicts the experimental temperature difference. Hence, using Eq. (8) to predict thermal shock behavior of treated glass as a function of initial crack size, we have

$\Delta T_{\mathrm{C}_{\mathrm{T}}}=102+1.23\left(l_{0}\right)^{-1 / 2}$.

We can also estimate the final length $\left(l_{\mathrm{f}}\right)$ of a crack after propagation by thermal shock. By inserting the retained rupture stress $\left(\sigma_{\mathrm{f}}=8 \mathrm{MPa}\right)$ into Eq. (16) results in $l_{\mathrm{f}}=1.9 \mathrm{~mm}$. In fact, it can be visually observed that after propagation by thermal shock the final crack lengths are $\approx 2.0 \mathrm{~mm}$ deep (Fig. 6). Hence calculations by Eq. (16) agree with the experimental $l_{\mathrm{f}}$.

Rearranging Eq. (9), one defines the number of cracks per unit area $\left(N_{\mathrm{S}}\right)$ that propagate simultaneously after thermal shock

$N_{\mathrm{S}}=\left(4 \pi l_{0} l_{\mathrm{f}}\right)^{-1}$.

From that equation we estimate that the number of surface cracks propagating simultaneously

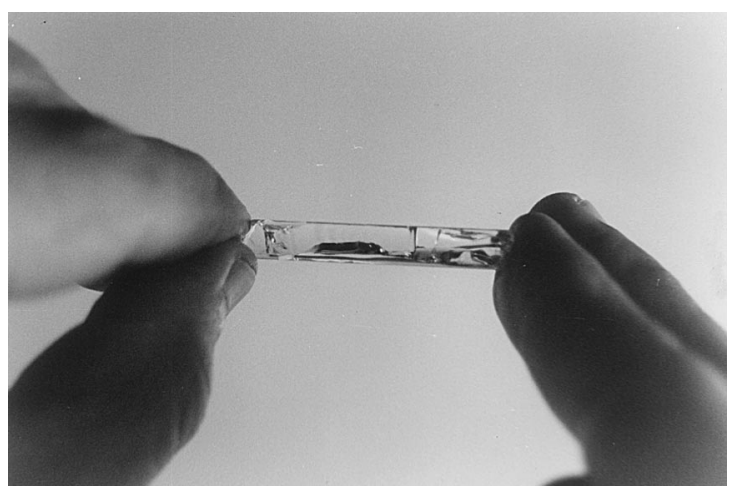

Fig. 6. Photograph of a part of a glass rod after thermal shock $\left(\Delta T>\Delta T_{\mathrm{C}}\right.$ ) showing longitudinal cracks which are larger than the transversal cracks. The specimen was not broken by thermal shock and diameter rod is $6 \mathrm{~mm}$.

on untreated glass rods should be in the range $130-220 \mathrm{cracks} / \mathrm{cm}^{2}$. However it was observed experimentally that only about 3 to $6 \mathrm{cracks} / \mathrm{cm}^{2}$ propagate in our samples (Fig. 6).

These results might, at first sight, indicate a discrepancy of over an order of magnitude with the $N_{\mathrm{S}}$ calculated by Hasselman's equation. However, despite that fact, it is important to stress that, after thermal shock $\left(\Delta T>\Delta T_{\mathrm{C}}\right)$, our rod samples cracked in both transversal and longitudinal directions. Additionally, most of the cracks were much longer in the longitudinal direction, as illustrated by Fig. 6. Since energy dissipation by longitudinally growing cracks was not evaluated in the theoretical calculations, this fact may explain the observed discrepancy.

Finally, we present equations for the critical temperature difference and final crack size of untreated glass, considering both the theoretical number of cracks (using the average $l_{0}=2.6 \times 10^{-5} \mathrm{~m} ; l_{\mathrm{f}}=1.9 \times 10^{-3} \mathrm{~m} \rightarrow N_{\mathrm{S}}=170$ cracks $\left./ \mathrm{cm}^{2}\right)$ and also that observed experimentally (3-6 cracks $\left./ \mathrm{cm}^{2}\right)$ :

$$
\begin{aligned}
& {\left[\Delta T_{\mathrm{C}_{\mathrm{UT}}}\right]_{\mathrm{Th}}=1.23\left(1+1.05 \times 10^{7} l_{0}^{2}\right)\left(l_{0}\right)^{-1 / 2},} \\
& {\left[l_{\mathrm{f}}\right]_{\mathrm{Th}}=4.76 \times 10^{-8}\left(l_{0}\right)^{-1},} \\
& {\left[\Delta T_{\mathrm{C}_{\mathrm{UT}}}\right]_{\mathrm{EXP}}=1.23\left(1+1.88 \times 10^{5} l_{0}^{2}\right)\left(l_{0}\right)^{-1 / 2},} \\
& {\left[l_{\mathrm{f}}\right]_{\mathrm{EXP}}=2.65 \times 10^{-6}\left(l_{0}\right)^{-1} .}
\end{aligned}
$$




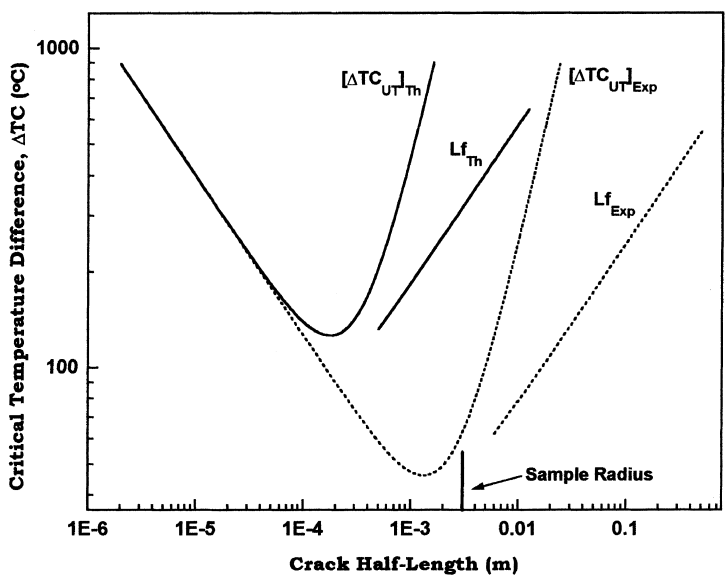

Fig. 7. Temperature difference $\left(\Delta T_{\mathrm{C}}\right)$ required to initiate crack propagation as a function of crack length. Experimental data (...); calculated values $(-)$ considering short cracks (located at the left hand size of the minimum. The final crack lengths are drawn for both experimental and calculated curves $\left(L_{\mathrm{FTh}}\right.$; $L_{\text {F Exp }}$ ) according to Eq. (14).

The curves generated by these equations are plotted in Fig. 7. It may be noted that, when using the experimental results for $N_{\mathrm{S}}$, the predicted final crack length reaches magnitudes that are longer than the sample diameter. In other words, the specimens should be broken, which did not, in fact, occur. Similar findings were also reported by Schneider et al. [27], based on different experiments from those described herein. However, it should be stressed that not all assumptions of the theoretical model are followed in the present case and thus, taking into account the approximations made in both theory and in the experiments, the observed differences can be considered quite reasonable.

\section{Conclusions}

Despite the fact that borosilicate glasses have a content of exchangeable ions that are not considered suitable for ion-exchange strengthening, an increment of thermo-mechanical properties was achieved with this technique.

The modulus of elasticity was determined by three experimental techniques: pulse-echo, exten- sometry, and flexural resonance; and estimated using Vickers microhardness. The direct experimental measurements indicated that ion-exchange increased the modulus of elasticity only $3 \%$, while the $E$ calculated from microhardness measurements is $40 \%$ larger. This difference is understandable, since the results of the first three experimental techniques are intermediate between the stiffened surface and the core of the tested body. Because the stiffened superficial layer is only a few tens of microns thick, it contributes little to the final average, while the $E$ calculated from microhardness data is determined mainly by the effect of ion-exchange on the surface.

Agreement was observed between the experimentally determined ratio of the critical temperature difference of chemically treated and virgin glass $\left(\Delta T_{\mathrm{C}_{\mathrm{T}}} / \Delta T_{\mathrm{C}_{\mathrm{UT}}}\right)$ and that calculated theoretically by the classical theory of thermal stresses.

The unified theory of thermal shock also provided a good description of the experimentally observed critical temperature difference for both treated and untreated glass. On the other hand, some disagreement was observed in the number of cracks that propagate by thermal shock. The calculated number of superficial cracks that propagate simultaneously is larger than the number observed experimentally. Despite that fact, taken into account the numerous assumptions in the theoretical derivations and the experimental errors, these results indicate agreement between theory and experiment.

\section{Acknowledgements}

The authors express their appreciation to Astra Brasil Ltda. for the donation of the Termex glass samples. We also thank Professors R.C. Bradt and D.P.H. Hasselman (USA), Walter Libardi, Hiroshi Tejima and Victor Pandolfelli of the Federal University of São Carlos, Professor Geraldo Lombardi of the University of São Paulo and Dr Günter Völksch of the Friedrich Schiller University in Jena, Germany; for their valuable assistance and suggestions. Funding by CNPq and PRONEX is deeply appreciated. 


\section{References}

[1] L.D. Pye, H.J. Stevens, W.C. LaCourse, Introduction to Glass Science, New York, Plenum, 1972, p. 451.

[2] A.A. Griffith, Philos. Trans. Roy. Soc. 221A (4) (1920) 162.

[3] F.M. Ernsberger, Ceram. Bull. 52 (3) (1973) 240.

[4] S.S. Kistler, J. Am. Ceram. Soc. 45 (2) (1973) 59.

[5] M.E. Nordberg, E.L. Mochel, H.M. Garfinkel, J.S. Olcott, J. Am. Ceram. Soc. 47 (5) (1962) 215.

[6] O. Peitl, E.D. Zanotto, Reforço Químico de Borosilicato Vitreo, Proceedings of the Seventh Brazilian Congress of Materials Science and Engineering - CBECIMAT, Brazil, Florianópolis, 1986, p. 459.

[7] A.M. Butaev, I.V. Vygorka, L.G. Perevozchikova, A.N. Yaborov, Steklo Keram. URSS 10 (1984) 11.

[8] W.D. Kingery, H.K. Bowen, D.R. Uhlmann, Introduction to Ceramics, Ch. 16, 2 ed., Wiley, New York, 1976.

[9] D.P.H. Hasselman, J. Am. Ceram. Soc. 46 (11) (1963) 535.

[10] M.E. Kipp, D.A. Krohn, D.P.H. Hasselmann, J. Am. Ceram. Soc. 57 (10) (1974) 457.

[11] M. Oguma, K. Chyung, K.Y. Donaldson, D.P.H. Hasselman, J. Am. Ceram. Soc. 70 (1) (1987) C-2.

[12] D.P.H. Hasselman, J. Am. Ceram. Soc. 52 (11) (1969) 600.

[13] J. Gebauer, D.A. Krohn, D.P.H. Hasselmann, J. Am. Ceram. Soc. 55 (4) (1972) 198.

[14] J.D. Mackenzie, J. Wakaki, J. Non-Cryst. Solids $38 \& 39$ (1980) 385.
[15] O. Peitl, Comportamento Termo-Mecânico de Borosilicato Vítreo Reforçado Quimicamente, Master of Science Dissertation, Federal University of São Carlos, Brazil, 1990.

[16] D.R. Uhlmann, N.J. Kreidl, Elasticity and Strength in Glasses, Ch. 2, Academic Press, New York, 1980.

[17] S.M. Wiederhorn, J. Am. Ceram. Soc. 52 (2) (1969) 99.

[18] F.V. Tooley, The Handbook of Glass Manufacture, 3rd ed., Books for Glass Industry Division, Ashlee, New York, vol. 2, 1984.

[19] R. Badaliance, D.A. Krohn, D.P.H. Hasselmann, J. Am. Ceram. Soc. 57 (10) (1974) 423.

[20] E.H. Ratclife, Glass Technol. 4 (4) (1963) 113.

[21] M. Ishitsuka, T. Sato, T. Endo, M. Shimada, J. Mater. Sci. Lett. 24 (1989) 4057.

[22] A.R. Migliore Jr., E.D. Zanotto, Glass Technol. 37 (3) (1996) 95.

[23] M. Yamane, J.D. Mackenzie, J. Non-Cryst. Solids 15 (1974) 153.

[24] W.E.S. Turner, S. English, J. Am. Ceram. Soc. 10 (1929) 551.

[25] J.M.F. Navarro, El Vidrio, Madrid, Consejo Superior de Investigaciones Científicas, Fundación Centro Nacional del Vidrio, 1991, p. 382.

[26] B. Lawn, Fracture of Brittle Solids, 2nd ed., Cambridge University, Cambridge, 1993.

[27] G.A. Schneider, R. Danzer, G. Petzow, Zum Thermoschockverhalten Spröder Werkstoffe, Fortschnittsberichte der Deutschen Keramischer Gesellschaft, Band 3, Haft B, 1988. 